\title{
Study on test of Gas-liquid energy conversion efficiency
}

\author{
Rongjun Sun ${ }^{1,3, a}$, Yang Sun ${ }^{2,3, a}$, Guojian Shao ${ }^{1, b}$, Mingwei $\mathrm{Lu}^{3, \mathrm{c}}$ and Yuting \\ $\mathrm{YaO}^{2, \mathrm{a}}$ \\ ${ }^{1}$ College of Mechanics and Materials, Hohai University, Nanjing, China \\ ${ }^{2}$ College of Harbour, Coastal and Offshore Engineering, Hohai University, Nanjing, China \\ ${ }^{3}$ Miao Hui Energy Technology Co. Ltd., Shanghai, China \\ aemail,sunyang_hhu@hhu.edu.cn bemail, gjshao@hhu.edu.cn cemail, 18834095@qq.com
}

\begin{abstract}
Keywords: Gas-liquid two-phase flow; high pressure air; conversion efficiency
Abstract. Development of hydraulic power energy with low water head is an effective supplementation for the traditional development of hydraulic power energy. How to effectively utilize the hydraulic power energy with low water head in nature is a problem now and the gas-liquid energy conversion efficiency is crucial to solve such problem. There are lots of parameters affecting the gas-liquid energy conversion efficiency, which mutually affect each other and whose relation is also very complicated. Therefore, it is necessary to determine their best configuration through the systematic test. This article describes the effects of three factors including diameter of the pump tube, diameter of intake tube, lift and intensity of pressure of air on the gas-liquid energy conversion efficiency and obtains their rules affecting the gas-liquid energy conversion efficiency through analyzing the test data and phenomena observed during test execution.
\end{abstract}

\section{Introduction}

In both nature and modern industrial production, it is very common to see the gas-liquid two-phase phenomenon, which closely relates to life and production of human [1]. Some scholars have performed some studies on the gas-liquid two-phase flow. Triplett et. al. [2] performed the experimental study on the air-water two-phase flow in the round tube with the inner diameters of 1.1 $\mathrm{mm}$ and $1.45 \mathrm{~mm}$ and small semi-triangular passages with the hydraulic power diameters of $1.09 \mathrm{~mm}$ and $1.49 \mathrm{~mm}$ and observed such flow patterns as bubble flow, stirring flow, slug flow, glug- annular flow and annular flow. Xu et. al. [3] performed the experimental study on vertically upward flow of the air-water in three small passages with the rectangular channel gap of $0.3,0.6$ and $1.0 \mathrm{~mm}$ under the heat insulation circumstance. Saisorn and Wongwises [4] performed the experimental study on such flow characteristics as flow pattern and pressure drop of air- steam liquid two-phase flow in a round tube with the inner diameter of $0.53 \mathrm{~mm}$ and length of $320 \mathrm{~mm}$ and observed the slug flow, throat-annular flow, stirring flow and annular-stream flow. In addition, Serizawa [5], Benjamin [6], De Vries [7], Wu and Gharib [8] studied the movement process of the bubbles in water through an indoor test, observed the movement characteristics of bubbles in liquid and analyzed the cause of different rising tracks of the bubbles, all of which mainly focus on study on the flow pattern and movement tracks, rather than the energy conversion test between air and liquid.

The hydraulic power energy in nature may be converted into high pressure gas through designing a special device and then the water is delivered to a higher place with the high pressure gas generated to lift the water to the place with the height of dozens or hundreds of meters with $2 \sim 3 \mathrm{~m}$ flow fall, rather than consuming the traditional gasoline, diesel or electric power resources. Such device utilizing the hydraulic power energy with low water head is an effective supplementation for development and utilization of the traditional hydraulic power energy, which has a brilliant application prospect. This article mainly concerns the water pressurizing efficiency of the high pressure gas in this device and analyzes the effects of some key parameters on the energy conversion efficiency through the test. 


\section{Testing Program}

According to different intensity of pressure and generation speed of gas, the high pressure gas collection system should have different structural designs to ensure that all high pressure gas may be collected and meet the requirement of the intensity of pressure and the water pump system may utilize the differential pressure energy which is delivered efficiently.

The factors mentioned above are the key ones to affect the energy conversion efficiency. As a comprehensive system, the liquid-gas energy conversion system has different links mutually affecting each other, which makes R\&D to improve the efficiency more difficultly. The research project consists of two experiments, including liquid-gas separation experiment: conversion into the high pressure gas with the potential energy of river water with fall and differential pressure energy water pump experiment: pumping water with the high pressure gas as energy. Now, the study on the differential pressure energy water pump experiment system is performed, with the experiment principles as shown in Figure 1.

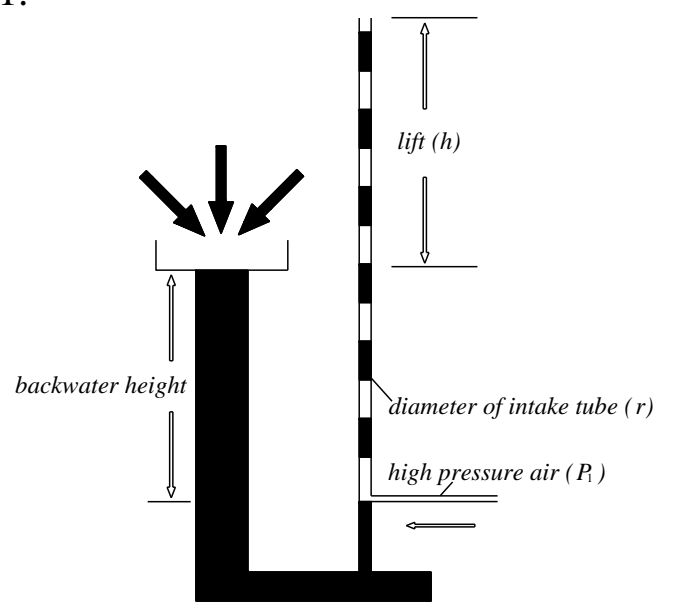

Fig. 1 differential pressure energy water pump experiment

The experimental device consists of water pump made of the PVC tubes, barometer, intelligent vortex shedding flowmeter and air compressor, with the device shown in Figure.

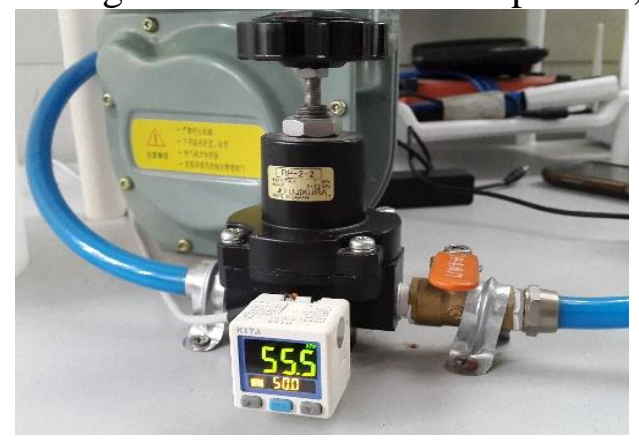

Fig. 2 air pressure regulator

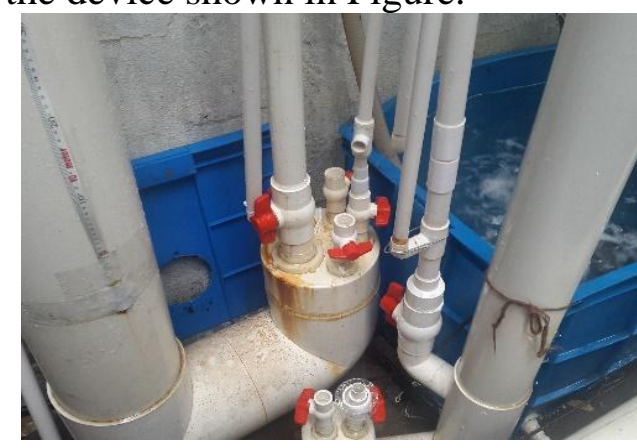

Fig. 3 water pump

During test execution, the outer diameter of the pump tube, diameter of the intake tube and lift and intensity of pressure of gas will affect the test data. Through analyzing different groups of test data, study on the effects of such factors as outer diameter of the pump tube, diameter of the intake tube and lift and intensity of pressure of the differential pressure energy water pump experiment system on the system efficiency and analyze the test data and phenomena observed during test execution.

\section{Test Result and Analysis}

As far as the general application environment is concerned, the flow fall is known. When the device is design, the intensity of pressure should be verified through test to ensure that it will meet the requirement of the subsequent differential pressure energy water pump and make the energy 
conversion efficiency the highest. Too high air inflow will affect water inflow, even result in cutoff, which will further affect the total energy to be utilized; if the air inflow is too low, there will be insufficient carrier to receive the energy conversion, which results in waste of some potential energy of water. During test execution, continually increase the intensity of pressure of the air through the air pressure regulator and change the diameter of the air inlet tube and lift of water to understand the effects of different diameters of the intake tube and lifts on the water pumping efficiency of the water pump under different intensities of pressure. Figure 4 to figure 7 shows the relationship between various factors and water pumping efficiency, and the water pumping efficiency equation is defined as:

$$
\eta=W_{\text {water }} / W_{\text {air }}=m g h / \int_{V_{1}}^{V_{2}} P d V=m g h / P_{1} V \ln \frac{P_{1}}{P_{2}}
$$

Where $h$ is the lift, $P_{1}$ is the high pressure air, and $P_{2}$ is atmospheric pressure.

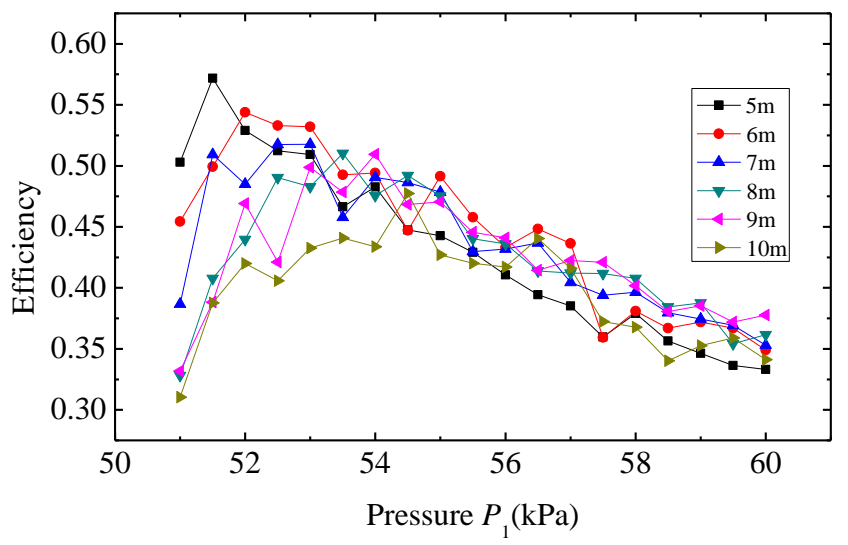

Fig. 4 gas pressure and water pumping efficiency

When the outer diameter of the pump tube is $25 \mathrm{~mm}$, backwater height is $5 \mathrm{~m}$ and the diameter of the intake tube is $3.5 \mathrm{~mm}$, the relation between the intensity of pressure and water pumping efficiency under the test condition with the lift rising to $10 \mathrm{~m}$ from $5 \mathrm{~m}$ is shown in Figure 4 . It can be seen from the Figure that the water pumping efficiency shows a trend of rising first and then falling along with increase of the intensity of pressure. When the intensity of pressure reaches $52 \mathrm{kPa}$, the water pumping efficiency reaches the maximum value and the high pressure gas will be wasted if the intensity of pressure is increased continually. Therefore, the water pumping efficiency will be reduced gradually.

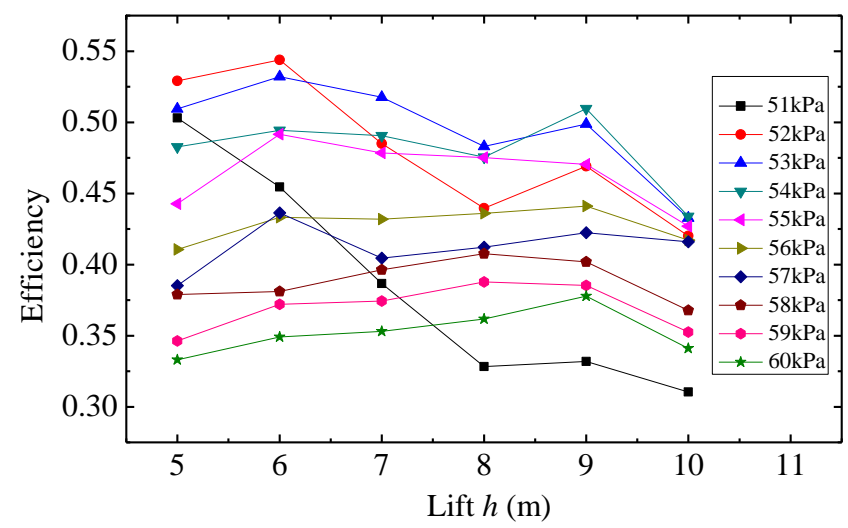

Fig.5 lift and water pumping efficiency

The test conditions with the outer diameter of pump tube of $25 \mathrm{~mm}$, backwater height of $5 \mathrm{~m}$ and diameter of intake tube is $3.5 \mathrm{~m}$, and intensity of pressure of $51 \sim 60 \mathrm{kPa}$ are shown in Figure 5. It is shown in the Figure that when the intensity of pressure is increased to about $52 \mathrm{kPa}$, the water 
pumping efficiency is higher when the lift is lower and the water pumping efficiency now reaches the maximum value. Along with increase of the intensity of pressure, the lift will be increased when the efficiency is highest and the highest efficiency is now much lower than the highest efficiency when the lift is lowest.
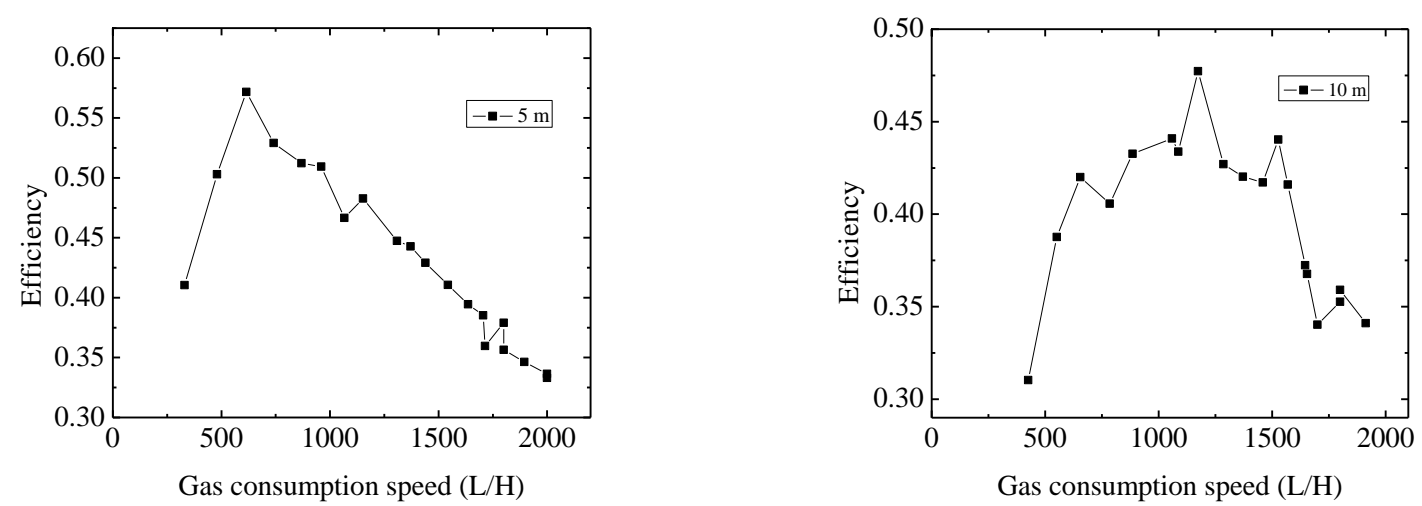

Fig.6 gas consumption speed and water pumping efficiency

The relation between the gas consumption speed $(\mathrm{L} / \mathrm{H}$, Liter/Hour) and water pumping efficiency is shown in Figure 6 when the outer diameter of pump tube is $25 \mathrm{~mm}$, backwater height is 5 $\mathrm{m}$, diameter of the intake tube is $3.5 \mathrm{~mm}$ and lift is $5 \mathrm{~m}$ and $10 \mathrm{~m}$. Along with gradual acceleration of the gas consumption, the water pumping efficiency shows a trend of rising first and then falling. When the gas consumption speed reaches a critical value, the water pumping efficiency is highest and further input of high pressure gas will not be utilized completely, but lost. Therefore, the water pumping efficiency will be reduced gradually.

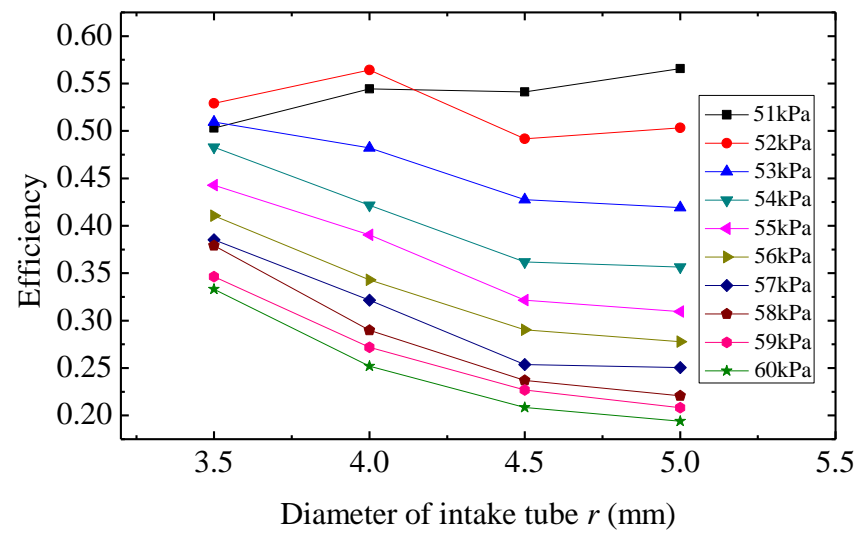

Fig. 7 diameter of intake tube and water pumping efficiency

For the same water inflow, we may design water inflow with different sizes and shapes, which should be determined according to the on-site environment to ensure the best energy conversion efficiency. Generally, the smaller the single water inflow unit, the higher the energy conversion efficiency, but the higher the construction cost and the lower the stability. The relation between the diameter of the intake tube and efficiency is shown in Figure 7, with the outer diameter of pump tube of $25 \mathrm{~mm}$, backwater height of $5 \mathrm{~m}$, lift of $5 \mathrm{~m}$ and intensity of pressure of $51 \sim 60 \mathrm{kPa}$. Under such circumstances, it shows an inversely proportional relationship between the diameter of intake tube and water pumping efficiency. It is shown in the Figure that the efficiency will appear a reduction process along with the increase of the diameter of intake tube. Meanwhile, it may be seen that the efficiency is the highest when the intensity of pressure is about $52 \mathrm{kPa}$. 


\section{Conclusions}

(1) When the backwater height is $5 \mathrm{~m}$ and the intensity of pressure is about $52 \mathrm{kPa}$, the pumping efficiency of the water pump reaches the maximum value.

(2) When the backwater height is constant, the lower the lift is, the higher the water pumping efficiency is. When the ratio of the backwater height to the lift is $1: 1$, the water pumping efficiency may reach about $57 \%$.

(3) The increase of the diameter of the intake tube will result in inadequate use of the high pressure air, which results in reduction of the water pumping efficiency. During test, the diameter of the intake tube should be reduced while ensuring that the high pressure air is completely input.

\section{Acknowledgements}

The research work described herein was funded by the National Natural Science Foundation of China (NSFC, Grant Numbers 51309151 \& 51278169) and by the Fundamental Research Funds for the Central Universities (Project Number: 2014B17414). Their financial support is gratefully acknowledged.

\section{References}

[1] Guo Liejin. Two-phase and Multi-phase Hydromechanics. Xi'an: Xi'an Jiaotong University Press, June 7, 2002.

[2] Triplett, K.A., Ghiaasiaan, S.M., Abdel-Khalik, S.I., and Sadowski, D.L. Gas-liquid two-phase flow in microchannels Part I: two-phase flow patterns. Int J Multiphase Flow, 1999, 25: 377-94.

[3] Xu, J.L., Cheng, P., and Zhao, T.S. Gas-liquid two-phase flow regimes in rectangular channels with mini/micro gaps. Int J Multiphase Flow, 1999, 25: 411-32.

[4] Saisorn, Wongwises. An inspection of viscosity model for homogeneous two-phase flow pressure drop prediction in a horizontal circular micro-channel. International Communications in Heat and Mass Transfer, 2008, 35(7): 833-838.

[5] Serizawa, A., Feng, Z.P., and Kawara, Z. Two-phase flow in microchannels. Experimental Thermal and Fluid Science, 2002, 26(6-7): 703-714.

[6] Benjamin, T.B. Hamiltonian theory for motions of bubbles in an infinite liquid. Journal of Fluid Mechanics, 1987, 181: 349-79.

[7] De Vries, A.W.Q., Biesheuvel, A., and Van Wijngaarden, L. Notes on the path and wake of a gas bubble rising in pure water. Int J Multiphase Flow, 2002, 28(11): 1823-1835.

[8] Wu, M., and Gharib, M. Exiperimental studies on the shape and path of small air bubbles rising in clean water. Physics of Fluids, 2002, 14(7): 49-52. 